\title{
VALIDITY AND RELIABILITY TEST OF SCREENING QUESTIONNAIRES TRAINING MOVEMENT APPROPRIATE TO ELDERLY PEOPLE
}

\author{
Cerika Rismayanthi \\ Ilmu Keolahragaan, Fakultas Ilmu Keolahragaan Universitas Negeri Yogyakarta. Jl. Colombo No. 1, \\ Karangmalang Depok, Sleman, Yogyakarta, Indonesia \\ cerika@uny.ac.id
}

\begin{abstract}
Increased age experienced by each person will end with elderly age group, which is vulnerable to various activities due to physiological function decrease occurred. On the other hand, elderly need to stay alive. Instead of socio-psychological aspects, muscular function, cardiovascular and balance and mobility aspects are important factors that support our bodies work. The assessment in this study use the questionnaire of "Appropriate Movement for the Elderly" distributed to personal trainers or instructors for elderly. The results of the validity test can be concluded that G4 (Press the arm in front of the chest) with $r$ count $=0.176<0.666$; G12 (Hyper-extension) with $r$ count $=0.176<0.666$; G14 (Ankle to left and right chest) with a value of $\mathrm{r}$ count $=-0.78<0.666$; G15 (Russian paver) with a calculated value of $\mathrm{r}=-0.78<0.666$; $\mathrm{G} 18$ (Turn the arm clockwise) with a value of $\mathrm{r}$ count $=$ 0.176; G36 (Cow Cat Attitude) with $r$ count $=-0.14$; G42 (Raise the sumo calf on the wall) with a calculated $\mathrm{r}$ value $=0.176<0.666$. Whilst, reliability test with Cronbach's Alpha value calculation was obtained at $0.734>0.60$, which shows various types of movements are reliable or consistent. It can be concluded that questionnaire about screening exercises that are suitable for the elderly prove is consistent for all questions and valid for 40 movements, while 7 other movements (pressing the arm in front of the chest, Hyper-extension, Knee wrists to the left and right chest, Russian paw, Turn the arm in the direction of the needle clock, Cow Cat Attitude, and Raise sumo, raise calf on the wall) were invalid or not suitable for physical activities.in elderly.
\end{abstract}

Keywords: physical activity, elderly, questionnaire, validity, reliability.

\section{UJI VALIDITAS DAN RELIABILITAS KUESIONER SKRINING GERAKAN LATIHAN YANG SESUAI DENGAN LANSIA}

\begin{abstract}
Abstrak
Pertambahan usia yang dialami oleh setiap orang akan berujung pada kelompok usia lansia, dimana rentan terhadap berbagai aktivitas karena adanya penurunan fungsi fisiologis yang terjadi. Di sisi lain, kebutuhan lansia untuk tetap dapat bertahan hidup harus dimiliki. Selain adanya aspek sosiopsikologis, aspek kemampuan otot, kardiovaskular dan keseimbangan serta mobilitas menjadi faktor penting untuk menunjang kerja tubuh. Pengukuran pada studi ini menggunakan kuesioner "Skrining Gerakan yang Cocok untuk Lansia" yang disebar kepada para personal trainer atau instruktur lansia. Diperoleh hasil uji validitas yang menyimpulkan bahwa G4 (Tekan lengan didepan dada) dengan $\mathrm{r}$ hitung $=0,176<0,666$; G12 (Hiperektansi) dengan $r$ hitung $=0,176<0,666$; G14 (Pergelangan lutut ke dada kiri dan kanan) dengan nilati $r$ hitung $=-0,78<0,666$; G15 (Puntir Rusia) dengan nilai $\mathrm{r}$ hitung $=-0,78<0,666$; G18 (Putar lengan searah jarum jam) dengan nilai $r$ hitung $=0,176$; G36 (Sikap Kucing Sapi) dengan nilai $r$ hitung $=-0,14$; G42 (Angkat sumo dan angkat betis di tembok) dengan nilai $r$ hitung $=0,176<0,666$. Sementara dalam uji reliabilitas diperoleh angka perhitungan nilai Cronbach's Alpha $0.734>0.60$, menunjukkan bahwa berbagai macam jenis gerakan yang ada termasuk reliabel atau konsisten. Dapat disimpulkan bahwa kuesioner mengenai skrining gerakan latihan yang sesuai dengan lansia terbukti konsisten dalam pemberian pertanyaan dan valid sebanyak
\end{abstract}


40 gerakan, sedangkan 7 gerakan lainnya (Tekan lengan didepan dada, Hiperektansi, Pergelangan lutut ke dada kiri dan kanan, Puntir Rusia, Putar lengan searah jarum jam, Sikap Kucing Sapi, dan Angkat sumo angkat betis di tembok) tidak valid atau tidak cocok untuk dilakukan oleh lansia saat beraktivitas fisik.

Kata Kunci : gerakan latihan, lanjut usia, lansia, validitas dan realibilitas

\section{PENDAHULUAN}

Masa perkembangan terakhir dalam hidup manusia adalah masa lansia. Disebut perkembangan di sini bukan berarti perkembangan seperti yang dialami remaja. Yang dimaksud adalah perkembangan psikologis dan sosial. Dalam hal ini tugas perkembangan pada lansia adalah tercapainya integritas dalam diri seseorang. Artinya ia berhasil memenuhi komitmen dalam hubungan dengan dirinya sendiri dan orang lain, menerima kelanjutan usianya, menerima keterbatasan kekuatan fisiknya, mungkin pula menerima penyakit yang dideritanya. Sebaliknya ia dapat pula menerima apapun perlakuan orang lain terhadap dirinya yang sesungguhnya merupakan cerminan perlakuan dirinya terhadap orang lain tersebut. Kalau seseorang tidak dapat mencapai integritas, maka ia akan mengalami keputusasan. Selain itu tugas perkembangan lansia adalah tentang komitmen moral. Lansia sebaiknya mempunyai komitmen untuk merasa mampu dan mempunyai penguasaan terhadap apa yang dihadapinya (Birren, Warner, Abeles, Gatz, \& Salthouse, 2006). Terakhir, ketiga komitmen tersebut di atas baik dalam perjuangan hidup secara fisik, ekonomik, maupun psikologik. Sehingga dibutuhkan kemampuan sosio-psikologis dalam kehidupan lansia untuk menunjang berbagai keterampilan di usia senja.

Secara garis besar, lansia harus mempunyai gairah dalam hidupnya. Dalam review meta-analisis mengenai bagaiman lansia merespon kehidupannya diperoleh hubungan antara kemampuan sosio-psikologis dengan adanya kecemasan yang menyelimuti pikiran banyak lansia. Untuk mengatasi kecemasan, diperoleh pernyataan bahwa terdapat hubungan yang potensial untuk latihan sebagai terapi depresi atau kecemasan, dan penggunaan aktivitas fisik sebagai bahan untuk memperbaiki kualitas hidup melalui penguatan harga diri, meningkatkan mood, mengurangi kecemasan, ketahanan terhadap stress dan meningkatkan kualitas tidur (Fox, 1999). Sehingga diharuskan bagi lansia untuk melibatkan aktivitas fisik dalam aspek memperbaiki hidupnya.

Lansia, usia sekitar 50 - 65 tahun (WHO, 2016), mengalami berbagai macam penurunan fungsi fisiologis, diantaranya fungsi otot, kardiovaskular, dll. kekuatan dan power otot dalam melakukan gerakan isometric, konsentrik dan eksentrik menurun sejak usia 40 tahun dan penurunan signifikan terjadi setelah usia 65-70 tahun (Porcari, Bryant, \& Comana, 2015). Lalu faktor keseimbangan dan mobilitas juga mengalami penurunan ketika sudah menginjak usia tersebut (Messier, Thompson, \& Ettinger, 1997; Porcari et al., 2015; Yamada \& Demura, 2009). Atas berbagai pertimbangan tersebut, dibutuhkan berbagai macam gerakan yang sesuai dengan kebutuhan lansia. Tentunya tidak bisa disamakan dengan gerakan yang biasa dilakukan oleh orang yang produktif di usia emas.

Maka dari itu diperlukan validasi dari para ahli (dalam hal ini personal trainer atau instruktur lansia) untuk mengetahui gerakan apa saja yang dianggap aman, mudah dan dapat mencegah atau memperlambat proses penuaan. Di lain pihak dapat membantu lansia begitu percaya diri dan mampu melakukan berbagai gerakan untuk kegiatan sehari-hari.

\section{METODE}

Studi ini menggunakan mixed-method (Donald Ary, Lucy Cheser Jacobs, Asghar Razavieh, 2009) agar dapat saling melengkapi data yang diperoleh, baik dari data kualitatif maupun kuantitatif. Data kualitatif diperoleh melalui wawancara lansia dan data kuantitaif melalui studi deskriptif menggunakan angket atau kuesioner "Skrining Gerakan untuk 
Lansia" sebagai instrumen. Kuesioner digunakan untuk memiliki gerakan latihan apa saja yang sesuai untuk lansia, dan beresiko kecil terhadap cedera atau ketidakseimbangan tubuh yang dapat menyebabkan jatuh pada lansia. Kuesioner yang disebar sudah melalui validasi pakar di bidang akademis, namun masih diperlukan validasi pakar dengan profesi sebagai praktisi, agar seluruh gerakan tersebut dapat diterapkan dalam aktivitas fisik sehari-hari bagi lansia.

Tabel 1. Rekomendasi jenis gerakan untuk lansia

\begin{tabular}{|c|c|c|c|}
\hline Latihan & Otot & No & Gerakan \\
\hline \multirow[t]{14}{*}{ Fleksibilitas } & Otot Dada & G1 & Peregangan Tulang Belakang \\
\hline & Otot Perut & G2 & Peregangan bahu \\
\hline & & G3 & Peregangan lumbar tulang belakang kiri dan kanan \\
\hline & Otot Lengan & G4 & Tekan lengan didepan dada \\
\hline & & G5 & Peregangan tricep kiri dan kiri \\
\hline & & G6 & Peregangan bisep berdiri kiri dan kanan \\
\hline & & G7 & Gator Bahu \\
\hline & Otot Bahu & G8 & Tarikan Romboid \\
\hline & & G9 & Peregangan lantai berbaring miring kiri dan kanan \\
\hline & & G10 & Gunting Lengan \\
\hline & & G11 & Sikap anak \\
\hline & & G12 & Hiperektansi \\
\hline & & G13 & Malaikat salju terbalik \\
\hline & Otot Kaki & G14 & Pergelangan lutut ke dada kiri dan kanan \\
\hline \multirow[t]{13}{*}{ Keseimbangan } & Otot Lengan & G15 & Puntir Rusia \\
\hline & & G16 & Angkat lengan sambil berdir \\
\hline & & G17 & Angkat lengan ke samping \\
\hline & & G18 & Putar lengan searah jarum jam \\
\hline & & G19 & Putar lengan berlawanan arah jarum jam \\
\hline & Otot Bahu & $\mathrm{G} 20$ & Ekstensi trisep membungkuk \\
\hline & & G21 & Superman dan perenang \\
\hline & & G22 & Angkat "Y" lantai \\
\hline & Otot Kaki & G23 & Angkat betis menghadap tembok \\
\hline & & $\mathrm{G} 24$ & Tendangan keledai kiri \\
\hline & & $\mathrm{G} 25$ & Latihan kuadrisep kiri dan kanan \\
\hline & & G26 & Bungkukan badan \\
\hline & & G27 & Jalan Sambil membawa Ball Medicine \\
\hline \multirow[t]{17}{*}{ Kekuatan } & Otot dada & $\mathrm{G} 28$ & Push up Tahan rendah modifikasi \\
\hline & Otot perut & $\mathrm{G} 29$ & Crunch Perut \\
\hline & & G30 & Pendaki Gunung \\
\hline & & G31 & Sentuh Tumit \\
\hline & & G32 & Latihan pengencangan perut \\
\hline & Otot lengan & G33 & Meninju \\
\hline & & G34 & Angkat tangan sambil berdiri \\
\hline & Otot bahu & G35 & Angkat lengan ke samping \\
\hline & & G36 & Sikap Kucing Sapi \\
\hline & & G37 & Superman dan perenang \\
\hline & & G38 & Push Up Telentang \\
\hline & Otot kaki & G39 & Squat \\
\hline & & G40 & Jalan samping \\
\hline & & G41 & Terjang mundur \\
\hline & & G42 & Angkat sumo angkat betis di tembok \\
\hline & & G43 & Bungkukan badan \\
\hline & & G44 & Angkat posisi Tandu Bersandar \\
\hline
\end{tabular}


MEDIKORA, Vol. 19 No. 2 Oktober 2020 - 115

Cerika Rismayanthi

\begin{tabular}{llll}
\hline Latihan & Otot & No & Gerakan \\
\hline Latihan & Duduk & G45 & \\
\cline { 2 - 4 } Berkelompok & Berdiri & G46 & \\
\cline { 2 - 4 } & $\begin{array}{l}\text { Berdiri Sambil } \\
\text { bergerak }\end{array}$ & G47 \\
\hline
\end{tabular}

\section{Pengolahan Data}

Data kuesioner yang sudah diperoleh kemudian dianalisi menggunakan IBM Statistics 20 menggunakan uji validitas (Pearson Correlation) dan uji reliabilitas (Cronbach's Alpha). Setelah perhitungan selesai, diperoleh hasil yang dapat menjelaskan data dari kuesioner yang telah disebar kepada para personal trainer atau instruktur.

\section{HASIL DAN PEMBAHASAN}

\section{Hasil}

\section{Uji Validitas}

Dalam uji validitas ini diperoleh 47 bentuk gerakan yang dianggap dapat dilakukan oleh lansia. Namun, untuk mengetahui apakah bentuk gerakan tersebut memang aman dan dapat dilakukan oleh lansia atau tidak, maka perlu dilakukan uji validitas dari para ahli (dalam hal ini personal trainer atau instruktur). Tabel 1. menunjukkan 47 gerakan yang dianggap dapat dilakukan.

Dari data yang tersebut pada Tabel 1, kemudian dilakukan uji validitas pada ahli untuk mengetahui mana saja gerakan yang bisa dilakukan lansia. Diperoleh hasil sebagai berikut; Ketentuan mengenai penentuan valid atau tidak, dapat dilihat dari $r$ tabel dan nilai Sig. (2tailed), maka diketahui dengan jumlah $\mathrm{N}=9$ (diartikan bahwa $\mathrm{N}=9$ karena setiap gerakan divalidasi oleh 9 orang personal trainer), kemudian didapat $\mathrm{R}$ tabel $=0.666$; dengan syarat, jika nilai Sig. (2-tailed) < 0,05 dengan Pearson Correlation bernilai positif, maka item soal angket tersebut dinyatakan valid.

Dapat disimpulkan bahwa, menurut pendapat personal trainer atau instruktur untuk lansia, dari 47 gerakan yang ada, nomor gerakan berikut: a). G4 (Tekan lengan didepan dada) dengan $r$ hitung $=0,176<0,666 ; b$ ). G12 (Hiperektansi) dengan $r$ hitung $=0,176<$ 0,$666 ; \mathrm{c}$ ). G14 (Pergelangan lutut ke dada kiri dan kanan) dengan nilati $r$ hitung $=-0,78<$ 0,666; d). G15 (Puntir Rusia) dengan nilai $r$ hitung = -0,78 < 0,666; e). G18 (Putar lengan searah jarum jam) dengan nilai $r$ hitung $=0,176$; f). G36 (Sikap Kucing Sapi) dengan nilai $r$ hitung $=-0,14 ; \mathrm{g}$ ). G42 (Angkat sumo angkat betis di tembok) dengan nilai $\mathrm{r}$ hitung $=$ $0,176<0,666$. Sehingga diperoleh data valid atas gerakan latihan yang cocok untuk lansia adalah sebagai berikut:

Tabel 2. Gerakan latihan yang dianggap valid

\begin{tabular}{ll}
\hline No & Gerakan \\
\hline G1 & Peregangan Tulang Belakang \\
\hline G2 & Peregangan bahu \\
\hline G3 & Peregangan lumbar tulang belakang kiri dan kanan \\
\hline G5 & Peregangan tricep kiri dan kiri \\
\hline G6 & Peregangan bisep berdiri kiri dan kanan \\
\hline G7 & Gator Bahu \\
\hline G8 & Tarikan Romboid \\
\hline G9 & Peregangan lantai berbaring miring kiri dan kanan \\
\hline G10 & Gunting Lengan \\
\hline G11 & Sikap anak \\
\hline G16 & Malaikat salju terbalik \\
\hline
\end{tabular}


MEDIKORA, Vol. 19 No. 2 Oktober 2020 - 116

Cerika Rismayanthi

\begin{tabular}{ll}
\hline No & Gerakan \\
\hline G17 & Angkat lengan ke samping \\
\hline G19 & Putar lengan berlawanan arah jarum jam \\
\hline G20 & Ekstensi trisep membungkuk \\
\hline G21 & Superman dan perenang \\
\hline G22 & Angkat 'Y" lantai \\
\hline G23 & Angkat betis menghadap tembok \\
\hline G25 & Tendangan keledai kiri \\
\hline G26 & Batihan kuadrisep kiri dan kanan \\
\hline G27 & Jalan Sambil membawa Ball Medicine \\
\hline G28 & Push up Tahan rendah modifikasi \\
\hline G29 & Crunch Perut \\
\hline G30 & Pendaki Gunung \\
\hline G31 & Sentuh Tumit \\
\hline G32 & Latihan pengencangan perut \\
\hline G33 & Meninju \\
\hline G34 & Angkat tangan sambil berdiri \\
\hline G35 & Angkat lengan ke samping \\
\hline G37 & Superman dan perenang \\
\hline G38 & Push Up Telentang \\
\hline G39 & Squat \\
\hline G40 & Jalan samping \\
\hline G41 & Terjang mundur \\
\hline G43 & Bungkukan badan \\
\hline G44 & Angkat posisi Tandu Bersandar \\
\hline G45 & Duduk \\
\hline G46 & Berdiri \\
\hline G47 & Berdiri Sambil bergerak \\
\hline
\end{tabular}

Ketujuh gerakan $(\mathrm{G} 4, \mathrm{G} 12, \mathrm{G} 14, \mathrm{G} 15, \mathrm{G} 18, \mathrm{G} 36, \mathrm{G} 42)$ dinyatakan tidak valid ( $p$ value $>0,05)$ sehingga tidak dicantumkan dalam Tabel 2., sedangkan 40 gerakan lainnya dianggap valid karena nilai signifikasinya diperoleh melalui $p$-value (Sig. 2-tailed) $<0,05$.

\section{Uji Reliabilitas}

Pengujian ini dimaksudkan untuk mengetahui tentang kekonsistenan dalam pemberian pertanyaan yang menyebabkan instruktur memiliki kemudahan dalam menjawab dan memiliki alur pertanyaan yang mudah dipahami. Adapun pengambilan keputusan dalam uji reliabilitas adalah sebagai berikut: 1) Jika nilai Cronbach's Alpha $>0.60$ maka kuesioner atau angket dinyakan reliabel atau konsisten; 2) Jika nilai Cronbach's Alpha $<0.60$ maka kuesioner atau angket dinyakan tidak reliabel atau tidak konsisten.

Tabel 3. Uji Reliabilitas

\begin{tabular}{ll}
\hline Cronbach's Alpha & .743 \\
\hline
\end{tabular}

Dengan nilai Cronbach's Alpha di angka $0.734>0.60$ dapat disimpulkan bahwa berbagai macam jenis gerakan yang ada dianggap reliabel atau konsisten.

\section{Pembahasan}

Aktivitas fisik memiliki peran penting dalam mencegah penurunan kemampuan tubuh di usia muda, mempertahankan fungsi tubuh, mengurangi faktor resiko disabilitas, membantu dalam mengecek sakit kronis seperti penyakit jantung, diabetes, artritis, atau 
beberapa tipe kanker dan perkembangan kualitas hidup (Moisescu, 2014). Namun dikarenakan adanya resiko jatuh yang begitu besar pada lansia (Yamada \& Demura, 2009), maka diperlukan banyak gerakan latihan yang cocok untuk lansia agar dapat menyokong seluruh aktivitas gerak sehari-hari.

Dari hasil wawancara yang dilakukan pada lansia disebutkan bahwa bentuk latihan fisik yang biasa dilakukan diantaranya bersepeda, senam aerobik dan berlari. Kebiasaan beraktivitas fisik dilakukan rutin seminggu tiga kali. Namun, mengalami keterbatasan tempat untuk beraktivitas dan jarang menggunakan alat tambahan ketika beraktivitas fisik, Kadang lansia mengalami penambahan beban latihan, namun mereka merasakan nyeri otot, kaku, nyeri persendian, nyeri saat melakukan gerakan membungkuk, pegal-pegal, terengahengah, dll. Maka dari itu, lansia menginginkan latihan dengan gerakan yang lambat, lebih menyenangkan, lebih banyak lansia yang terlibat agar dapat berkomunikasi dan membuat pikiran menjadi lebih fresh.

Sejauh ini para lansia beranggapan belum ada model latihan fisik yang melibatkan aspek sosiologis dan psikologis. Kendala yang dihadapi para lansia diantaranya seperti gerakan lompat, gerakan membungkuk, angkat beban dan gerakan koordinasi kaki dan tangan secara bersamaan.

Maka dilakukan pengujian validitas dan reliabilitas kuesioner skrining gerakan latihan untuk lansia yang bertujuan agar saat pemberian aktivitas tidak terjadi malpraktik yang bisa membahayakan, seperti jatuh, cedera, dan ketidakleluasaan dalam bergerak. Mudah jatuh berhubungan erat dengan ketidakseimbangan tubuh, semakin besar berat badan seseorang semakin buruk kemampuan keseimbangan tubuhnya (Gao et al., 2019). Dari hasil penelitian validitas dan reliabilitas skrining gerakan, maka diperoleh 40 gerakan sebagai berikut;

Banyaknya gerakan yang tersedia pada Tabel 2. menunjukkan bahwa menurut para personal trainer atau instruktur untuk lansia, gerakan tersebut aman dilakukan, cocok untuk usia lanjut. Dimulai dengan berbagai macam gerakan peregangan, tarik-menarik, keseimbangan, kekuatan otot, dll. Hasil wawancara dengan para instrruktur lansia menyebutkan bahwa sebesar 57,14\% instruktur lansia melakukan latihan dengan waktu minimal 30 menit. Sebanyak 5 dari 7 instruktur mengatakan bahwa latihan yang dilakukan sudah sesuai prinsip kebugaran dengan intensitas rendah-sedang. Komponen kebugaran dalam melatih lansia meliputi kemampuan aerobik, keseimbangan, daya tahan, kekuatan, kelenturan, dan kecepatan Tentunya ketika melakukan gerakan harus diawasi oleh instruktur, tidak bisa melakukan seorang diri, dikarenakan adanya resiko jatuh yang tinggi (Yamada \& Demura, 2009).

Sebagai contoh, kemampuan keseimbangan akan berkurang ketika berat badan bertambah (Gao et al., 2019), sebuah studi di Jepang menjelaskan bahwa pada lansia yang sehat akan diperoleh hubungan yang negatif terhadap kondisi lemak dan lingkar pinggang (Ito et al., 2019). Dengan kata lain, semakin banyak timbunan lemak dan lebarnya lingkat pinggang akan berkorelasi positif terhadap kemungkinan resiko jatuh lansia, namun pada lansia yang sehat dengan kondisi lemak dan lingkar pinggang yang normal, maka akan meminimalisir.resiko jatuh.

Dengan adanya variasi pilihan gerakan pada Tabel 3, menunjukan adanya keluasaan dalam bergerak bagi usia lanjut dalam beraktivitas fisik. Namun tak bisa dipungkiri, 5 dari 7 instruktur mengatakan lansia terlihat mengalami kesulitan dalam melakukan gerakan. Munculnya kesulitan lansia dalam melakukan gerakan mengakibatkan instruktur memilih cara untuk melakukan banyak pengulangan, membantu dalam menyelesaikan gerakan dan membuat gerakan menjadi lebih sederhana, diikuti dengan penambahan beban dari satu sesi ke sesi berikutnya. Ketika dilakukan wawancara pada lansia pun menyebutkan bahwa sebagai orang yang diberikan latihan, mereka lebih memilih untuk melakukan latihan dengan gerakan yang mudah dilakukan.dan dalam bentuk permainan. 
Sesuai dengan berbagai macam studi sebelumnya yang menerangkan tentang aktivitas fisik akan memberi manfaat kesehatan untuk lansia, mempertahankan fungsi tubuh secara mandiri (Evans \& Grimby, 1995), meningkatkan kualitas hidup mereka (Cress et al., 2004), meningkatkan stabilisasi postur dan pola jalan pada lansia dalam mengurangi kejadian jatuh yang sering terjadi (Messier et al., 1997). Selain aspek fisik, lansia juga butuh dukungan dari aspek sosio-psikologis (Kaufman \& Wolff, 2010).. Dengan adanya dukungan sosial dari sekelilingnya, lansia akan memiliki tekanan darah yang rendah (Birditt, Newton, Cranford, \& Ryan, 2016), menurunkan angka kematian (Holt-Lunstad, Smith, \& Layton, 2010) dan meningkatkan fungsi kognitif (Gow, Corley, Starr, \& Deary, 2013). Banyak instruktur berpendapat bahwa belum ada latihan fisik yang memadukan aspek sosiopsikologis dengan aktivitas fisik. Model latihan fisik yang dianjurkan oleh para instruktur diantaranya aktivitas fisik intensitas rendah - sedang yang dilakukan rutin 3 kali seminggu, gerakan yang mudah, sederhana dan menyenangkan, mengutamakan keseimbangan dan kekuatan.

\section{SIMPULAN}

Kuesioner mengenai skrining gerakan latihan yang sesuai dengan lansia terbukti konsisten dalam penyampaian pertanyaan bagi instruktur khusus lansia dan disebutkan valid untuk 40 gerakan, sedangkan 7 gerakan lainnya (Tekan lengan didepan dada, Hiperektansi, Pergelangan lutut ke dada kiri dan kanan, Puntir Rusia, Putar lengan searah jarum jam, Sikap Kucing Sapi, dan Angkat sumo angkat betis di tembok) tidak valid atau tidak cocok untuk dilakukan oleh lansia untuk beraktivitas fisik.

\section{DAFTAR PUSTAKA}

Birditt, K. S., Newton, N. J., Cranford, J. A., \& Ryan, L. H. (2016). Stress and negative relationship quality among older couples: Implications for blood pressure. Journals of Gerontology - Series B Psychological Sciences and Social Sciences. https://doi.org/10.1093/geronb/gbv023

Birren, J. E., Warner, K. S., Abeles, R. P., Gatz, M., \& Salthouse, T. A. (2006). Handbook of the Psychology of Aging. In Handbook of the Psychology of Aging. https://doi.org/10.1016/B978-0-12-101264-9.X5000-9

Cress, M. E., Buchner, D. M., Prohaska, T., Rimmer, J., Brown, M., Macera, C., ... Chodzko-Zajko, W. (2004). Physical activity programs and behavior counseling in older adult populations. Medicine and Science in Sports and Exercise. https://doi.org/10.1249/01.MSS.0000145451.08166.97

Donald Ary, Lucy Cheser Jacobs, Asghar Razavieh, C. K. S. (2009). Introduction to Research in Education Eighth Edition. In

Evans, W. J., \& Grimby, G. (1995). Muscle Performance and Structure in the Elderly as Studied Cross-sectionally and Longitudinally. The Journals of Gerontology Series A: Biological Sciences Medical Sciences. https://doi.org/10.1093/gerona/50a.special_issue.17

Fox, K. R. (1999). The influence of physical activity on mental well-being. Public Health Nutrition. https://doi.org/10.1017/S1368980099000567 
Gao, X., Wang, L., Shen, F., Ma, Y., Fan, Y., \& Niu, H. (2019). Dynamic walking stability of elderly people with various BMIs. Gait and Posture. https://doi.org/10.1016/j.gaitpost.2018.11.027

Gow, A. J., Corley, J., Starr, J. M., \& Deary, I. J. (2013). Which social network or support factors are associated with cognitive abilities in old age? Gerontology. https://doi.org/10.1159/000351265

Holt-Lunstad, J., Smith, T. B., \& Layton, J. B. (2010). Social relationships and mortality risk: A meta-analytic review. PLoS Medicine. https://doi.org/10.1371/journal.pmed.1000316

Ito, T., Kawakami, R., Tanisawa, K., Miyawaki, R., Ishii, K., Torii, S., ... Higuchi, M. (2019). Dietary patterns and abdominal obesity in middle-aged and elderly Japanese adults: Waseda Alumni's Sports, Exercise, Daily Activity, Sedentariness and Health Study (WASEDA'S Health Study). https://doi.org/10.1016/j.nut.2018.05.029

Kaufman, P., \& Wolff, E. A. (2010). Playing and protesting: Sport as a vehicle for social change. Journal of Sport and Social Issues. https://doi.org/10.1177/0193723509360218

Messier, S. P., Thompson, C. D., \& Ettinger, W. H. (1997). Effects of long-term aerobic or weight training regimens on gait in an older, osteoarthritic population. Journal of Applied Biomechanics. https://doi.org/10.1123/jab.13.2.205

Moisescu, P. C. (2014). The Social Integration of Elders Through Free-time Activities. Procedia - Social and Behavioral Sciences. https://doi.org/10.1016/j.sbspro.2014.01.909

Porcari, J. P., Bryant, C. X., \& Comana, F. (2015). Exercise Physiology (Foundations of Exercise Science) 1st Edition.

WHO. (2016). WHO | Proposed working definition of an older person in Africa for the MDS Project. World Health Organization.

Yamada, T., \& Demura, S. ichi. (2009). Relationships between ground reaction force parameters during a sit-to-stand movement and physical activity and falling risk of the elderly and a comparison of the movement characteristics between the young and the elderly. Archives of Gerontology and Geriatrics. https://doi.org/10.1016/j.archger.2007.10.006 